\title{
The effects of processing parameters on the formation of oxide layers in aluminium alloys using plasma electrolytic oxidation technique
}

https://doi.org/10.1515/jmbm-2021-0013

Received Jun 24, 2021; accepted Aug 15, 2021

\begin{abstract}
The plasma electrolytic method of oxidation (PEO) is a technique that is increasingly being used in industry to produce protective coatings and other surface treatments. The emphasis is then placed on the dielectric breakdown that repeatedly occurs across the surface of the workpiece. There is significant potential for more effective process control. Key study areas include the interrelation of electrical conditions, electrolyte composition, coating microstructure, and growth rates. With specific goals in terms of coating performance and energy efficiency, an attempt is made to identify key points that are likely to simplify this. The research aims to identify the optimized range of input parameters when the oxide layer is formed using the DC supply in the silicate-based electrolyte on $\mathrm{Al} 6061$ substrate. For developing an oxide layer on $\mathrm{Al} 6061$, a silicate-based electrolyte containing $\mathrm{Na} 2 \mathrm{SiO} 3(10 \mathrm{~g} / \mathrm{L}), \mathrm{KOH}(2 \mathrm{~g} / \mathrm{L})$, and $\mathrm{KMnO} 43$ (g/lit) is applied. At the optimal parameter of DC supply with $190 \mathrm{~V}$ and $1.5 \mathrm{~A}$, the maximal adoption of $\mathrm{Mn}$ particles was observed to be 34 percent.
\end{abstract}

Keywords: plasma electrolytic method of oxidation, Al6061, micro arc oxidation

\footnotetext{
Priya Jadhav: Symbiosis Institute of Technology (SIT), Symbiosis International (Deemed University), Lavale, Pune - 412 115, Maharashtra State, India

*Corresponding Author: Arunkumar Bongale: Symbiosis Institute of Technology (SIT), Symbiosis International (Deemed University), Lavale, Pune - 412 115, Maharashtra State, India, E-mail: arunbongale1980@gmail.com

Satish Kumar: Symbiosis Institute of Technology (SIT), Symbiosis International (Deemed University), Lavale, Pune - 412 115, Maharashtra State, India; Symbiosis Centre for Applied Artificial Intelligence, Symbiosis International (Deemed University), Lavale, Pune - 412 115, Maharashtra State, India
}

๖ Open Access. (๑ 2021 Jadhav et al., published by De Gruyter. (cc) BY License

\section{Introduction}

The most pressing real-world issues are determining environmentally friendly techniques for applications where high-efficiency coatings are required. An advanced solution to the crisis could be technological developments and future technologies research areas that combine technologies of controlled changes in the physicochemical properties of structural components surface layers. Aluminium and its alloys are extensively used in various applications due to their superior mechanical and chemical properties. As a result, engineering solutions that combine mechanical properties and coating development on the treated metal surface in a single process are very appealing. This method results in high adhesion and stable doping components on the surface [1]. The oxidation method of coating for the surface of the metal is the method that enhances the characteristics of the outer layer of metal. Few capable and effective methods are physical and chemical vapor deposition, anodizing, oxidation method, sol-gel, thermal spray, ceramic coating [2]. The scanning micro-arc oxidation method shows improvement in microstructure and corrosion resistance with lubrication time and discharge distribution [3]. For automotive components, the oxide coatings can be useful in repainting cracks of metallic surfaces on the exterior part of components. The oxide layers have an outstanding improvement in fatigue resistance than the hard anodic coatings [4]. The micro-arc method of oxide coating builds uniform, adherent, strong coatings on metal components of critical shapes at normal temperature using a simple process setup.

The majority of surface hardening is done by hard anodizing or galvanizing. The primary distinction between the methods is the formation of the oxide layer. In the case of hard anodizing, galvanizing produces a barrier oxide layer that is more modified. The passive barrier layer is formed beneath the oxide layer To protect the base material. On the other hand, the PEO method is more influential because it creates a strong oxide porous layer with a uniform structure [5].

This work is licensed under the Creative Commons Attribution 4.0 
Aluminium is a reactive material with excellent corrosion resistance and sometimes a thin film of $2-5 \mathrm{~nm}$ passive film stable in $\mathrm{PH}$ values ranging from 4 to 8.5 [6]. When aluminium is combined with different iron, silicon, copper, magnesium, and Manganese weights to form an alloy, it results in increased hardness, corrosion resistance, and other properties. The formation of cohesive oxide coatings or oxide layers on aluminium alloys doped with transition metal ions is mainly achieved by impregnating porous or easily oxidized substrates with a suitable methodology associated with thermal decomposition. PEO method is based on anodizing, in which an electrolytic bath contains the electrolyte, and a voltage of about $80 \mathrm{~V}$ is supplied between anode and cathode. The solution is frequently highly acidic and is primarily used to develop nanostructure microstructures.

In PEO processing, oxidation occurs by combining metal atoms with oxygen atoms in the plasma of electrolyte discharges. The higher heat generated by the discharges forms a thicker and harder layer on the substrate. The microarc oxidation method is the most flexible one for the composition of the coating layer compositions. These coatings have influential adhesion properties, improved hardness, and wear resistance [7]. Hence often preferred in the application requirement are high wear and low friction coefficient [6]. The aviation components with high corrosion resistance requirements can potentially surface coating methods across oxide coatings or ceramic coatings [8]. The material composition is an important factor in improving corrosion resistance. Surface modification methods can be used to modify the secondary phases of oxide formed on the outer layer. The plasma coating has proven to be highly wettable with the surface, resulting in strong, long-lasting bonds.

Oxide coatings can be used to repair cracks in metallic structures in the automotive industry. The scanning micro-arc oxidation method enhances microstructure and corrosion resistance with lubrication time and discharge distribution [3]. As for micro-arc oxidation method input parameters and discharge, characteristics are important one the method proposed to carry out using high voltage DC to check the effect on surface integrity of the coating. Researchers are investigating various lightweight metals for applications such as automotive [9, 10,11, 12]. Parameters such as electrolyte material and composition, oxidation timing, current and voltage inputs, and additives are important for the micro-arc process of oxide coating [13] Following is a review of papers divided into different categories based on process and testing. A 6061 aluminium alloy was used in the micro-arc oxidation method with $\mathrm{KOH}$ and $\mathrm{Na}_{2} \mathrm{SiO}_{3}$. The microstructure of the formed coat- ing was investigated for phase changes and uniformity. The phases $\alpha \mathrm{Al}_{2} \mathrm{O}_{3}$ appeared in the initial phase of the coating and converted to $\gamma \mathrm{Al}_{2} \mathrm{O}$ as the oxidation method time increased. The density of the micro discharges has significantly increased. Also, the pore density was higher during the initial coating phases, and the crater appeared later in the time scale. Based on the experiment data, it was discovered that the coating growth was parabolic due to the presence of a higher amount of in the electrolyte and that a higher amount of $\mathrm{Na}_{2} \mathrm{SiO}_{3}$ gives a higher hardness to the coating [14]. The use of a silicate-based electrolyte in the PEO process results in the formation of the discharges at the boundaries of the layer with a higher percentage of silicon. As a result, the layer becomes uneven. The surface properties are identified by dendrites of silicon oxide in this oxidation method [15].

There are also a few important conclusions about the particle compositions used in the electrolytes. Yong Lian et al. used a micro-arc oxidation method for $\mathrm{Ti}_{6} \mathrm{Al}_{4} v$ alloy with SiC-containing electrolytes. During the microstructure study, the effect of the Si element was dominant in the coating layer. The pores on the coating have shrunk, and the coated layer has a uniform distribution of $\mathrm{Si}$. At room temperature, $\mathrm{SiC}$ is dielectric, but it is a good conductor of electricity at higher temperatures. It absorbs more electrons and reduces spark formation at higher temperatures, resulting in a denser and thinner coating [16].

Zheng-yang et al. improved the corrosion resistance of a $\mathrm{Zr}$ alloy by incorporating graphene, which formed a $\mathrm{ZrO}_{2}$ the coating on the substrate. Graphene was discovered to be a good diffusion barrier. Because of the strong coating, the coefficient of friction decreases along with the wear volume. The microstructure study discovered that with $\mathrm{Si}$ based electrolytes, the formation of pores decreases. These pores are filled with GO particles, which strengthen the material against wear and corrosion. The presence of go particles did not affect the composition of the coating. The coating layer is primarily composed of $\mathrm{t}-\mathrm{ZrO}_{2}$ and $\mathrm{m}-\mathrm{ZrO}_{2}$ phases [17].

According to a thorough literature review, the plasma oxide layer is formed by applying an alternate current. The AC type of current causes the local big arc ablation phenomenon, damaging the samples [18]. The input modes are bipolar, alternating current, and pulsed direct current, but very little work is done on applying DC to the process. It is uncertain which method of power voltage supply and voltage output is best suited for MAO technology, convergence, and energy consumption. In the oxidation process, $\mathrm{KMnO}_{4}$ acts as a strong oxidizing agent. out experiments, but only a limited amount of research has been done on as, $\mathrm{KMnO}_{4}$ an additive $[6,19,20]$. As a result, it is valuable to 
evaluate the surface modifications caused by the addition of Mn particles. Hence, it becomes essential to study DC inputs of current and voltage parameters on oxide layer formation and additive. Here, the attempt is made to formulate the oxide layer using DC voltage around $200 \mathrm{~V}$. Also, the use of DC power supply is very common for different applications in the industry; hence the study needs to be done to use and improve the formation of the homogenous layer of metal oxide.

In the current study, the plasma electrolytic oxidation for Al6061 alloy is studied to variation the primary parameter of current and voltage type. The effect of the direct current is studied for the plasma electrolytic oxidation method. The microstructure and surface properties are investigated. Different compositions of electrolytes and the duration of the process are varied for creating samples.

\section{Mechanism of electrolysis}

There are two types of aspects responsible for oxide layer formation - intrinsic and extrinsic factors. Intrinsic parameters are the composition and $\mathrm{pH}$ value of the electrolyte. The extrinsic factors consist of the type of voltage currently applied to the system, other inputs like the temperature of the electrolyte. The intrinsic parameters promote the passivating layer on the outer surface. The elements in the electrolyte form oxysalt that acts as the oxygen source for the oxidation reaction. As per the research conducted in the area, $\mathrm{KOH}$ and $\mathrm{NaOH}$ are identified as the best electrolyte for maintaining $\mathrm{Ph}$ between 7 to 12 . Silicate, phosphate, aluminate electrolytes are often used in the composition due to the breakdown voltage expected during the process as a prerequisite. They minimize the sparking voltage that enhances the outer surface quality. The chemicals like $\mathrm{Al}_{2} \mathrm{O}_{3}$ produced in the process, accelerate the growth rate and thickness of the coating. The mixture formed at the anode consists of the alumina phases and mullite.

All of the basic PEO mechanisms are observable in the formation process of coatings on aluminium alloys in specified solutions. Using the existing concepts of the PEO mechanism in high-energy fields, we can identify the four stages of the oxide coating formation process. Before the electric discharge ignition, the oxidation process begins with the formation of the primary oxide layer. The second step is to electrochemically break this layer and create a bunch in the discharge channel. The third phase is a bit turbulent, consisting of the gas phases of element and igniting micro-arc discharges. While the fourth stage is the condensation of these oxide phases as they transition from micro-arc to arc discharge.

I. Reactions at the cathode:

$$
\begin{aligned}
2 \mathrm{Al}+2 \mathrm{H}_{2} \mathrm{O}+2 \mathrm{OH}^{-} & =2 \mathrm{AlO}_{2}^{-}(\mathrm{aq})+3 \mathrm{H}_{2} \\
\mathrm{Al}+4 \mathrm{OH}^{-} & =\mathrm{Al}(\mathrm{OH})_{4}^{-}
\end{aligned}
$$

$$
\mathrm{Al}(\mathrm{OH})_{3}+\mathrm{OH}^{-} \rightarrow \mathrm{Al}(\mathrm{OH})_{4}^{-}
$$

May occur in composition.

II. The discharge occurs at high voltage resulting in oxidation of water. As a result, the water is ionized and reacts with aluminium ions forming the aluminium oxide.

$$
\begin{gathered}
2 \mathrm{Al}^{3+}+3 \mathrm{O}^{2-} \rightarrow \mathrm{Al}_{2} \mathrm{O}_{3} \\
2 \mathrm{H}_{2} \mathrm{O}+3 \mathrm{O}^{2-} \rightarrow \mathrm{Al}_{2} \mathrm{O}_{3} \\
2 \mathrm{H}_{2} \mathrm{O} \rightarrow \mathrm{O}_{2}+4 \mathrm{H}^{+}+4 \mathrm{e}^{-}
\end{gathered}
$$

III. The chemical formation in the electrolyte are [21]

$$
\begin{gathered}
\mathrm{Al}^{3+}+3 \mathrm{OH}^{-} \rightarrow \mathrm{Al}(\mathrm{OH})_{4} \downarrow \\
2 \mathrm{Al}^{3+}+3 \mathrm{SiO}_{2}{ }^{2-} \rightarrow \mathrm{Al}_{2}\left(\mathrm{SiO}_{3}\right)_{3}
\end{gathered}
$$

Chemical reduction by the dissolution of the outer layer

$$
\begin{gathered}
\mathrm{Al}_{2} \mathrm{O}_{3}+2 \mathrm{OH}^{-}+3 \mathrm{H}_{2} \mathrm{O} \rightarrow 2 \mathrm{Al}(\mathrm{OH})_{4} \rightarrow 2 \mathrm{Al}(\mathrm{OH})_{3} \downarrow+2 \mathrm{OH}^{-} \\
\mathrm{Al}(\mathrm{OH})_{4}^{-}+\mathrm{H}_{2} \mathrm{O} \rightarrow \mathrm{Al}_{2} \mathrm{OH} \downarrow+2 \mathrm{H}_{2} \mathrm{O}+\mathrm{OH}^{-} \\
\mathrm{Al} \rightarrow \mathrm{Al}^{3+}+3 \mathrm{e}^{-}
\end{gathered}
$$

IV. Metal deposition occurs at the anode as

$$
\begin{gathered}
\mathrm{Al}^{3+}+3 \mathrm{e}^{-} \rightarrow \mathrm{Al} \\
2 \mathrm{MnO}_{4}{ }^{-} \rightarrow \mathrm{MnO}_{4}{ }^{2-}+\mathrm{MnO}_{2}+\mathrm{O}_{2} \uparrow
\end{gathered}
$$

Reaction 13 [20] occurs due to the strong oxidizing nature of . While reaction 8 resulted in the deposition of the electrolyte compounds during the process. 


\section{Materials and methods}

Al6061 was chosen to investigate the effect of PEO- oxide layer formation. Spectroscopic analysis (BAIRD-DV6) was performed following ASTM E415-14 standards to determine the chemical composition of the test specimen, and it was discovered that the procured material falls within the standard specification. Table 1 displays the spectroscopic analysis results as well as the standard composition of $\mathrm{Al} 6061$ material.

Table 1: Result of chemical analysis increasing percentage alloying element in aluminium 6061.

\begin{tabular}{llll}
\hline $\begin{array}{l}\text { Sl } \\
\text { No }\end{array}$ & Element & $\begin{array}{l}\text { Percentage } \\
\text { (wt\%) }\end{array}$ & $\begin{array}{l}\text { Specification } \\
\text { aluminium 6061 }\end{array}$ \\
\hline 1 & $\mathrm{Cu}$ & 0.28 & $0.15-0.4$ \\
2 & $\mathrm{Mn}$ & 0.15 & 0.15 \\
3 & $\mathrm{Mg}$ & 1 & $0.8-1.2$ \\
4 & $\mathrm{Zn}$ & 0.25 & 0.25 \\
5 & $\mathrm{Cr}$ & 0.2 & $0.04-0.35$ \\
6 & $\mathrm{Ti}$ & 0.15 & 0.15 \\
7 & $\mathrm{Si}$ & 0.6 & $0.4-0.8$ \\
8 & $\mathrm{Fe}$ & 0.7 & 0.7 \\
9 & $\mathrm{Al}$ & 96.67 & Remaining \\
\hline
\end{tabular}

The micro-arc oxidation is conducted using a lab-based setup, as shown in Figure 2. The electrolytic chamber is made up of three layers. The inner chamber is made of stainless steel and is surrounded by copper tubes that can hold water or coolant channels. The liquid is used to extract heat from the electrolyte and keep the temperature stable. For safe earthing, the copper tubes are surrounded by asbestos insulating material.

The anode was made of an $\mathrm{Al}$ alloy, and the other electrode was made of stainless steel. The electrolyte solution is silicate-based and includes $\mathrm{Na}_{2} \mathrm{SiO}_{3}, \mathrm{KOH}$, and water. The rectangular sample had a width of $40 \mathrm{~mm}$, a thickness of $10 \mathrm{~mm}$, and $100 \mathrm{~mm}$. The samples were gritted with 800 and 1200 \# SiC sandpaper before being rinsed with water. Voltages ranging from 0 to $190 \mathrm{~V}$ DC were used for the oxidation, which lasted 5 to 15 minutes. Finally, to prepare for testing, the treated samples were dried and cleaned with distilled water. The chemical analysis of alloying elements in aluminium 6061 is shown in Table 1.

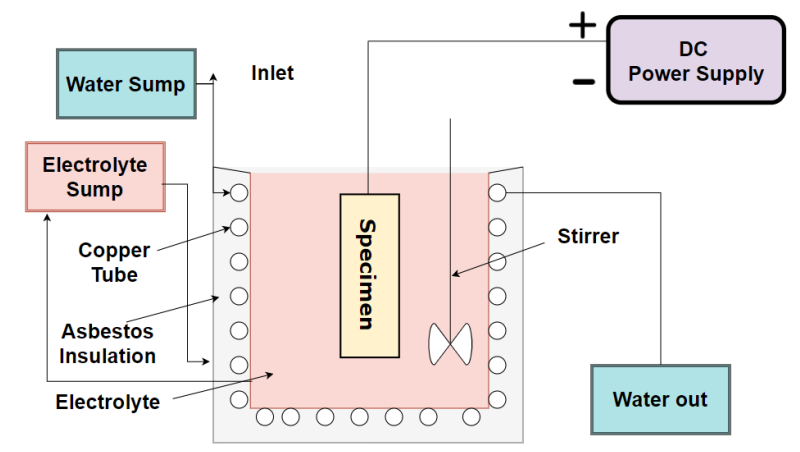

(a)

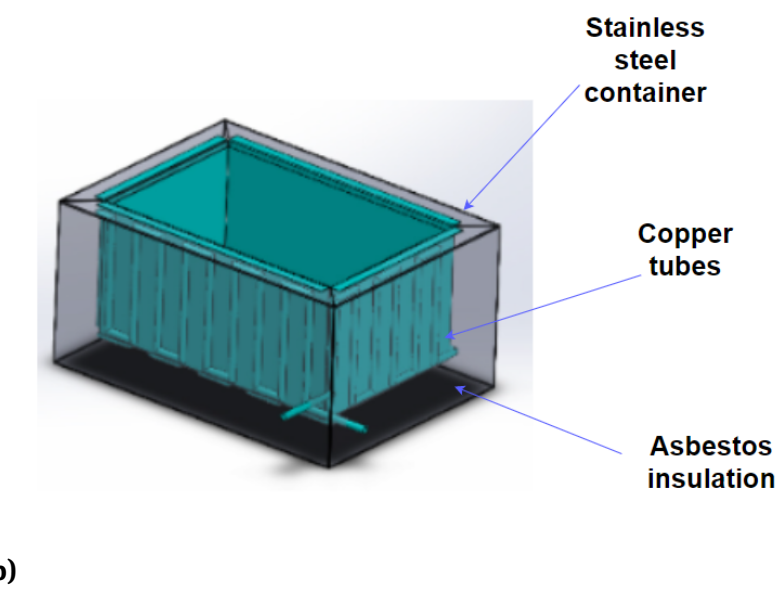

Figure 1: a) Schematic setup of plasma arc oxidation method with controlled cooling; b) Electrolyte tank with cooling arrangements.

\section{Configuration of experiments}

Table 2 shows the ranges of input parameters like DC voltage, the current, composition of the electrolyte, and additives. Few experiments were conducted without additives while the rest are with percentage addition of $\mathrm{KMnO}_{4}$. For all experiments, the composition is kept constant. The duration of the process and V-I values are changed.

The temperature during the process is measured by a thermal imager (Testo 872) for measuring temperature variation at the electrodes and electrolyte. A field emission scanning electron Microscope (FEI Nova NanoSEM 450) was employed to study the surface morphology of the oxide layer. The distribution of aluminium and oxygen was determined by Energy Dispersive Spectrometer (EDS: Bruker XFlash 6I30). The thickness of the oxide layer is analyzed using a coating thickness gauge.

Wire EDM is used to cut a piece of $2 \mathrm{~mm}$ thickness for SEM and EDX testing. Few samples were examined for surface microstructure for elemental distribution, while the 


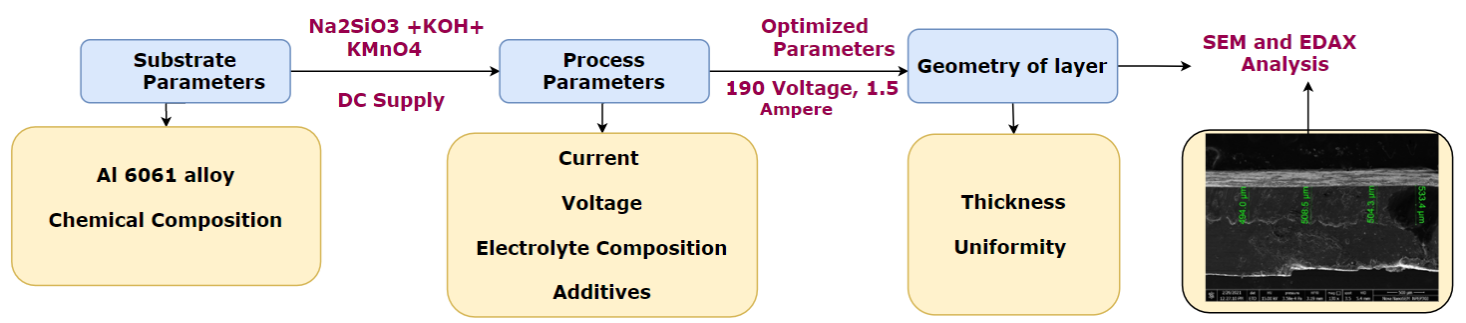

Figure 2: Optimized parameters obtained from experiments.

Table 2: Experimentation parameters.

\begin{tabular}{lll}
\hline $\mathrm{Sr}$ & Parameter & Range - Units \\
No. & & \\
\hline 1 & Voltage & $150-190 \mathrm{~V} \mathrm{DC}$ \\
2 & Current & $0-38 \mathrm{~A} \mathrm{DC}$ \\
3 & Time & $5-15 \mathrm{Minutes}$ \\
4 & Temperature & $26-75^{\circ} \mathrm{C}$ \\
5 & $\begin{array}{l}\text { Distance between } \\
\text { the electrodes }\end{array}$ & 35 to $50 \mathrm{~mm}$ \\
6 & $\begin{array}{l}\text { Additive } \\
7\end{array}$ & $\mathrm{KMnO}_{4}-3(\mathrm{~g} / \mathrm{lit})$ \\
& Electrolyte ele- & $\mathrm{Na}_{2} \mathrm{SiO}_{3}(10 \mathrm{~g} / \mathrm{L}), \mathrm{KOH}(2 \mathrm{~g} / \mathrm{L})$ \\
\hline & & \\
\hline
\end{tabular}

rest of the samples were examined for cross-sections showing the depth of the formed oxide layer. As a result, the thickness and uniformity of the oxide layer can be determined using FESEM.

\section{Result and discussion}

The $\mathrm{Al} 6061$ alloy is studied to form the oxide layer, uniformity, thickness of the layer in cross-section, and elemental distributions. In addition, the variation in the percentage weights of elements like $\mathrm{Al}, \mathrm{O}, \mathrm{Si}$, and $\mathrm{Mn}$ was studied in depth.

\subsection{Oxide layer formation}

The oxide layer formation has occurred at two different ranges. The layer thickness is around 200 microns for voltage values 150 and 190, but for parameters, $188 \mathrm{~V}$ and 4.5, $\mathrm{A}$ and $150 \mathrm{~V}$ and $7.5 \mathrm{~A}$, the layer thickness improved significantly up to 500 microns, as seen in Figure 4. Hence it is essential to check the depth-wise formation of the oxide layer. The possible goal of the research is to investigate the development of the oxide layer under various input condi-

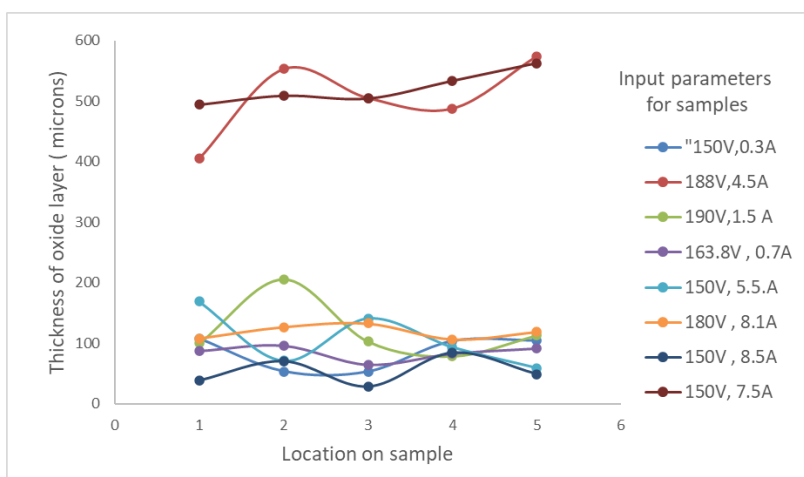

Figure 3: Relation between input parameters and oxide layer growth.

tions. As a result, the intensity growth of the oxide layer may reflect substrate adhesion and thickness uniformity. SEM pictures taken across the sample depth can be used to verify this.

The SEM microscopic cross-section of the substrate of the oxide layer formed on the surface is shown in Figure 5. The oxide layer is dense and uniformly distributed over the area. Earlier trials showed a very thin, insignificant layer for the current values $1 \mathrm{~A}$ and $70 \mathrm{~V}$. Hence the parameter values are increased to get the range for creating the oxide layer. The next set of experiments were conducted between the voltages 120 to $188 \mathrm{~V}$. The current variation is due to the formation of the oxide coatings. When the oxide layer first forms on the surface, it acts as a barrier film. The current has begun to fall as the oxide film begins to thicken over the duration of the process. The change in current values is caused by the formation of pores. Hence the drop in current is due to the stopping of the growth of some pores due to the growth of other pores [22]. The pore formation phenomena during the oxide layer development are after the initial growth of the oxide layer. The pore can be formed rapidly at the initial stages then increase followed by reduction due to longer oxidation time [23]. 

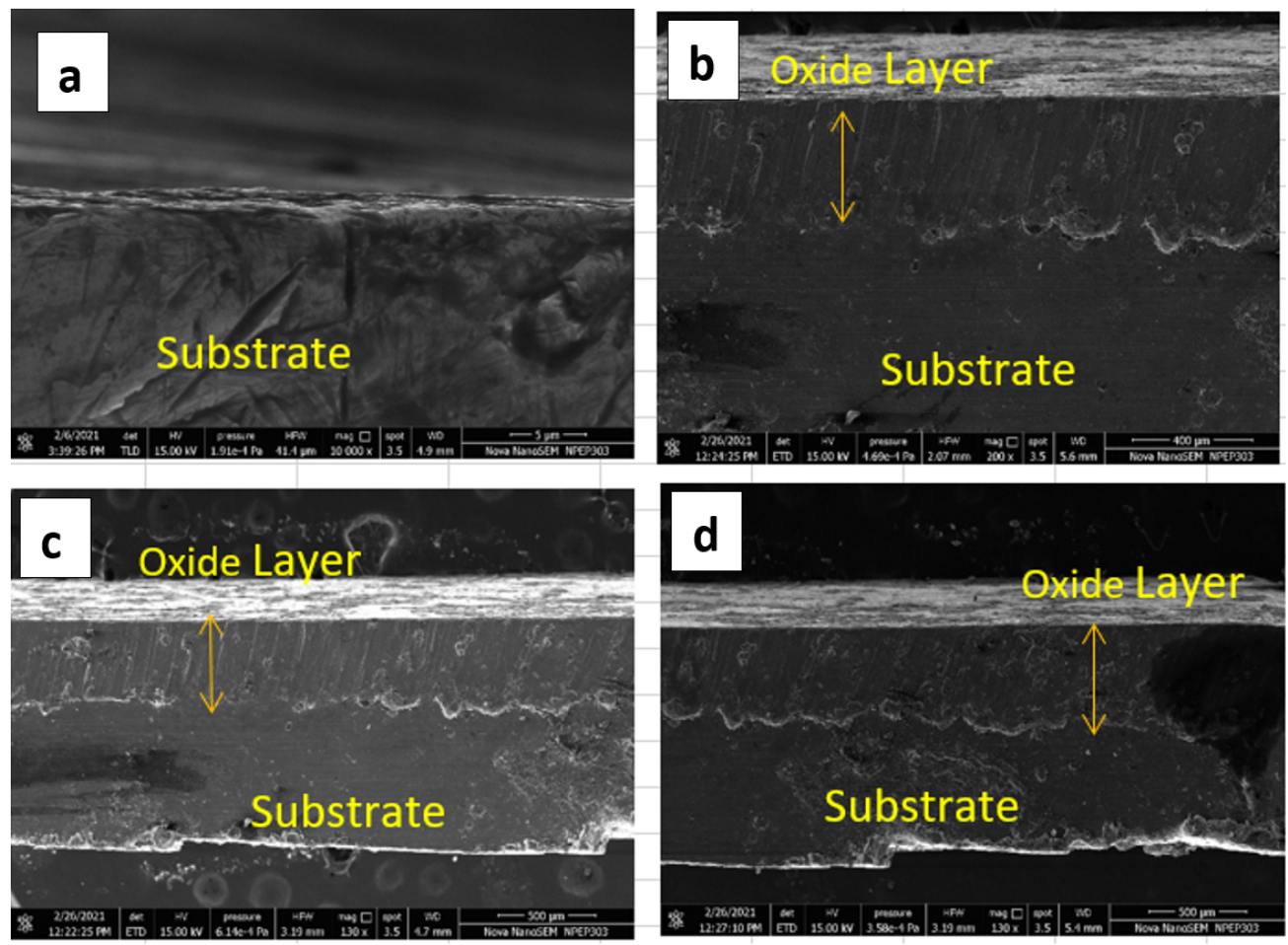

Figure 4: SEM images of Sample surfaces at a) Al 6061 (without oxide layer); b) at $150 \mathrm{~V}$ - and 5.5-Amp Current; c) At $180 \mathrm{~V}$ and $8.1 \mathrm{~A} \mathrm{~d}$. $188 \mathrm{~V}$ and $4.5 \mathrm{~A}$.

\subsection{Effect of current at different voltage}

The temperature of the electrolyte is maintained for the oxidation process due to a controlled type of cooling. In comparison, the current chronograms show a reduction in current values for supplied voltages to time. As process time increases, the current value reduces up to zero current ampere or few milliamperes. It may happen due to a reduction in load due to changes in discharge properties. As per the pore formation theory [24], current variation affects the porosity formation. Therefore the study of the porosity needs to be done to identify the current variation behavior with the time of the process and composition of the electrolyte.

Initially, voltage and temperature increase up to the first few minutes and then becomes constant as observed in experimental readings. The voltage $188 \mathrm{~V}$ shows higher temperature but which goes on reducing due to controlled cooling. The circulated water around the electrolyte container extracts heat and keeps the electrolyte at a constant temperature. For aqueous solutions, the discharges need high voltage values to conquer the dielectric strengths of the gas released during the process. The overall plasma sustain at low values of the currents is required. But the high values constraint the breakdown events to happen at an uncontrolled speed. The electrolysis is conducted with

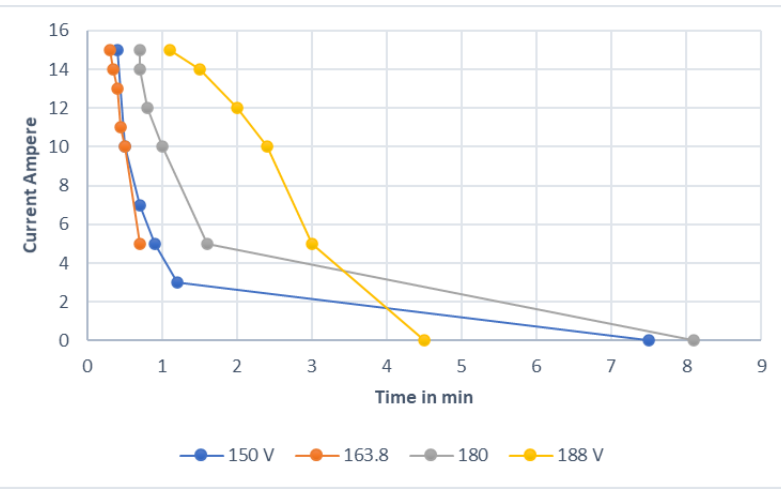

Figure 5: Current-time chronograms at different voltages.

molten metal composition to form micro-level discharges at low voltages to overcome such effects. After developing the micro-arc, the voltages become stable to allow the oxide layer to form over the surface [25].

\subsection{Effect of variation in electrode configuration}

Few experiments were carried out using varying the position of the electrode. Initially, the single electrode of Al 6061 alloy is used as the anode, while the stainless-steel tank 


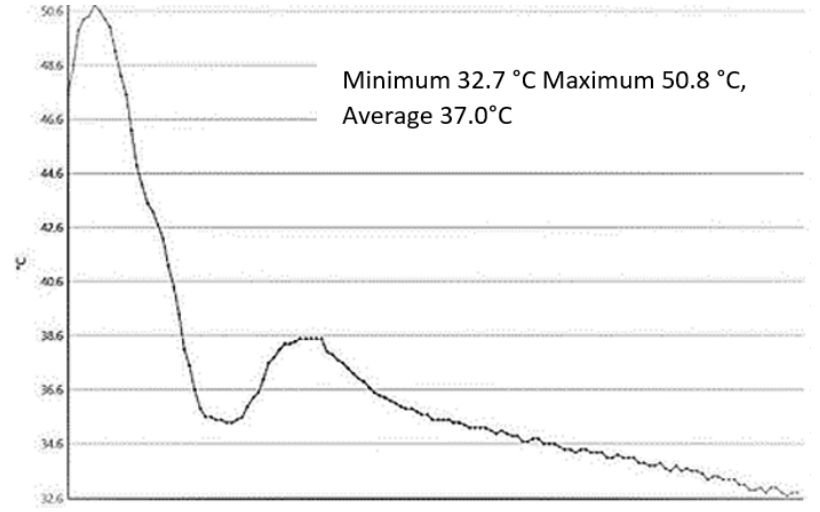

(a)

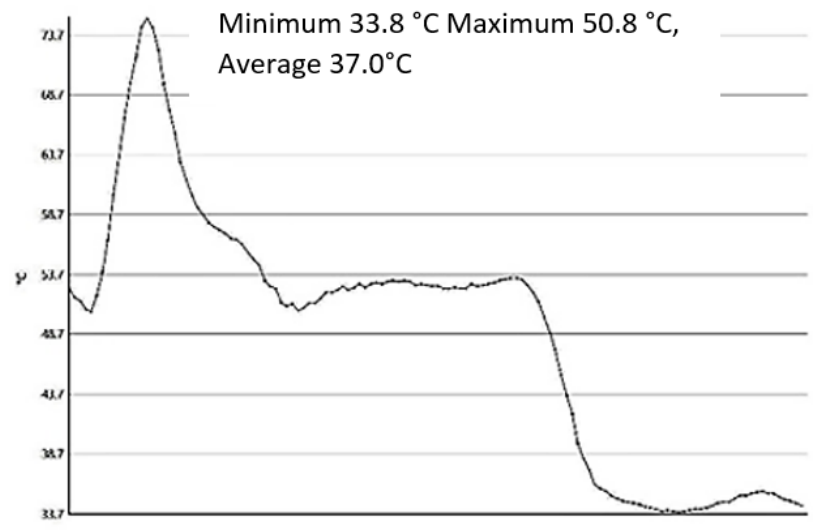

(b)

Figure 6: Temperature profile at the electrode when a) stainless Al electrode used with stainless steel tank b) Two electrodes of steel and Al alloy electrode are used.

was the cathode. Due to lower values of DC voltage, the micro-arc was not prominent. The temperature variation seems to be very abrupt with time. Figure 7 shows that the temperature reduces gradually from $73.7^{\circ} \mathrm{C}$ to $33^{\circ} \mathrm{C}$. The change in temperature of the electrolyte remains uniform for a longer duration. It also supports the ion deposition on the anode [26].

The temperature variation when a single electrode and two electrodes were used for experiments is analyzed, as shown in Figure 8. The heat generation is directly relative to the temperature difference and the thermal coefficient of expansion. The temperature variation was low when using a single electrode, resulting in poor heat generation. When two electrodes were used with a smaller gap between them, the high-temperature difference generates a significant amount of heat, resulting in an oxide layer forming at lower input parameters. Because of the greater temperature difference, the heat rejection in the electrode was greater. As a result, electrolyte cooling is required to maintain discharge characteristics.

\subsection{SEM micrographs}

The oxide layer formation with a voltage greater than 180 $\mathrm{V}$ and current values ranging from $4.5 \mathrm{~A}$ to $8.1 \mathrm{~A}$ is shown in Figure 8. Various SEM images indicate the peaks of the elements. This study aims to identify the traces and distribution of the elements, mainly $\mathrm{Al}, \mathrm{O}, \mathrm{C}, \mathrm{Si}$, and $\mathrm{Mn}$. The higher amount of the aluminum and oxygen element helps to improve the formation of $\mathrm{Al}_{2} \mathrm{O}_{3}$ molecules in the oxide layer. The $\%$ of $\mathrm{C}$ occurred around 29 to $52 \%$ atomic weight at voltage range $150 \mathrm{~V}$ and $190 \mathrm{~V}$ and current values $1.5 \mathrm{~A}$ and $1.7 \mathrm{~A}$. Simultaneously, the oxygen ranges from 33 to $44 \%$ for the same values of the parameters. On the other hand, the Si occurs at traces. Therefore, the presence of these elements can be considered as the optimum value of the input parameters.

\subsection{SEM / FESEM analysis at cross-sectional area}

The samples formed at different electrolyte composition shows the different characteristics morphologically. The change in the texture of the surface also can be seen with the naked eye. The difference in the surface finish is also noticeable for every sample. To understand the development of the layer, the SEM and FEM are taken in two ways. Surface SEM gave the distribution of the composition. In comparison, the cross-sectional FESEM measures the coating thickness and local changes in the composition of the material. The oxide layer started developing, which can be visible at a magnification of 600 microns.

The FESEM is used on the surface of the samples to determine the element distribution. The percentile elements show that the SI and O elements have improved significantly. In contrast, cross-sectional testing demonstrates the uniformity and thickness of the oxide layer.

The percentage variation of different elements is seen in Figures 10a and 10b for non-coated and coated samples of $\mathrm{Al} 6061$. The $\mathrm{Al}$ reduces from $83.2 \%$ to $63.4 \%$. The compound formation due to the oxide layer can be identified from the elemental peaks. After oxide coating over the outer surface presence of Si, Mn, C, Na can be observed. 


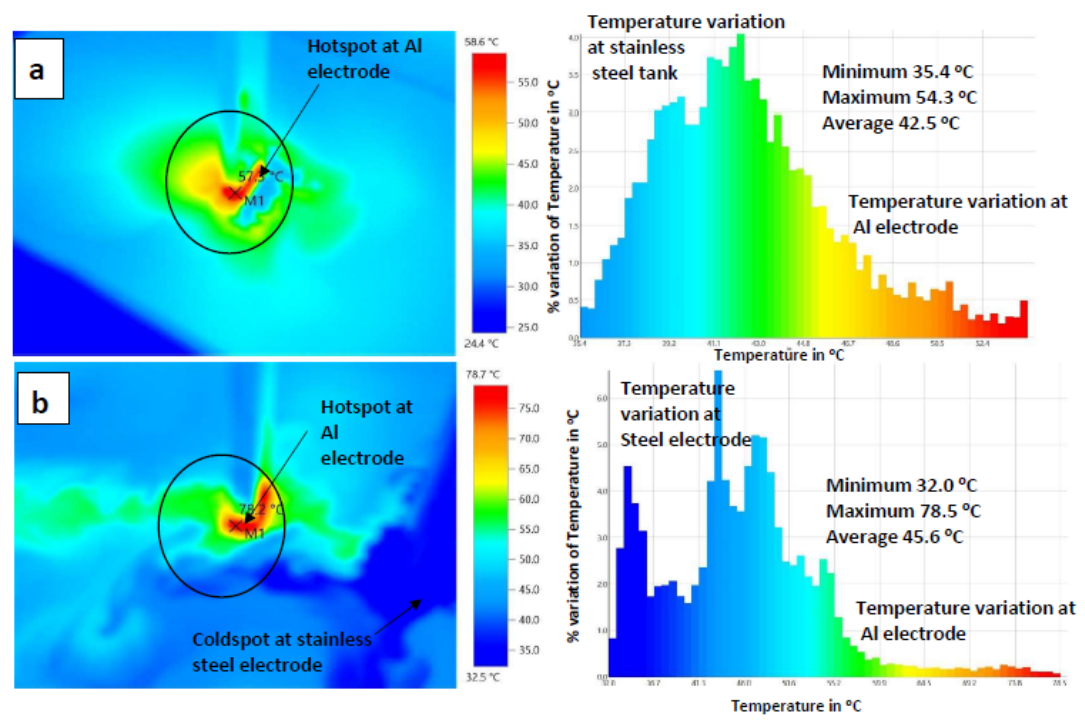

Figure 7: Temperature variation at the a) steel tank and electrode b) at two electrodes.

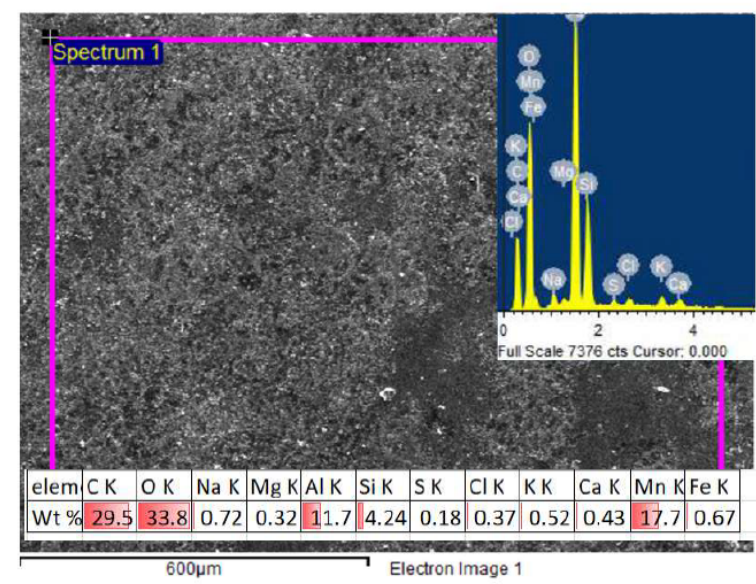

(a)

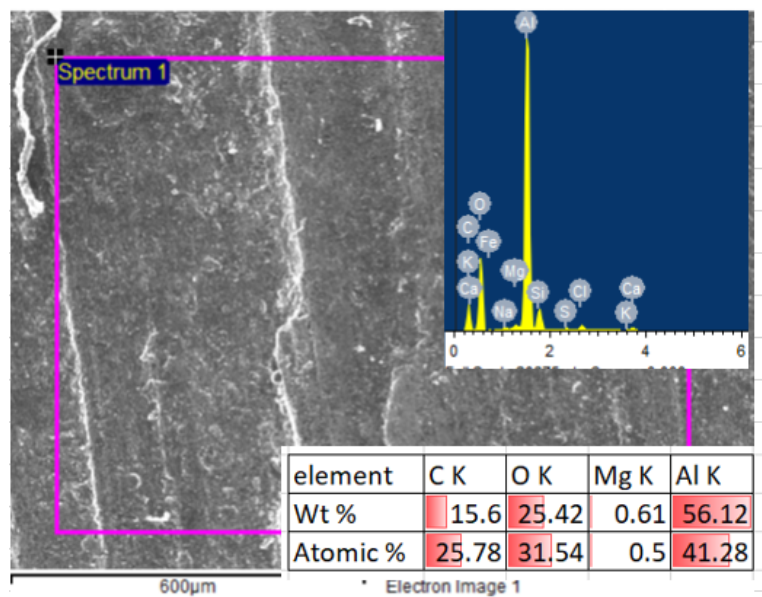

(b)

Figure 8: SEM graphs at the surface layer.
The cross-sectional study of the oxide layer is formed uniformly for samples treated at voltages greater than $150 \mathrm{~V}$, as seen in Figure 11a and at voltage $188 \mathrm{~V}$ in Figure 11b. As a result, at this breakdown voltage, the oxide layer begins to form more uniformly. The oxide layer formed up to 90 microns for current values less than $1 \mathrm{~A}$. As the current increases, the oxide layer grows to a thickness of 500 microns. The graph represents the elemental distribution of $\mathrm{C}, \mathrm{Si}$, $\mathrm{Al}$, and $\mathrm{O}$ particles in a layer. A significant layer has been observed to form on the substrate. The high metal to oxygen particle ratio signifies the formation of the stoichiometric oxide, which is the optimum value $[27,28]$.

\subsection{Elemental analysis}

The percentage variation of the different elemental weights signifies the formation of the compounds in the oxide layer. An increase in the percentage of $\mathrm{Si}$ and $\mathrm{O}$ indicates the formation of the aluminates in the layer that can be taken for further study as the oxide layer started developing, which is visible at a magnification level of more than 500 microns (as seen in Figures 10 a,b and 11 a, 11b) the layers need to be more dense and thick. Hence this elemental analysis is useful for improving the oxide layer morphology.

Other particles of additive materials also can improve the properties very significantly. In this research, the KMNO4 is added as a strong oxidizing agent as per a review of the literature [19]. The presence of the Mn particle also improves the surface finish. The percentage distribution of the various elements is depicted in Figure 12. It has been discovered that a higher current value does not support Mn 


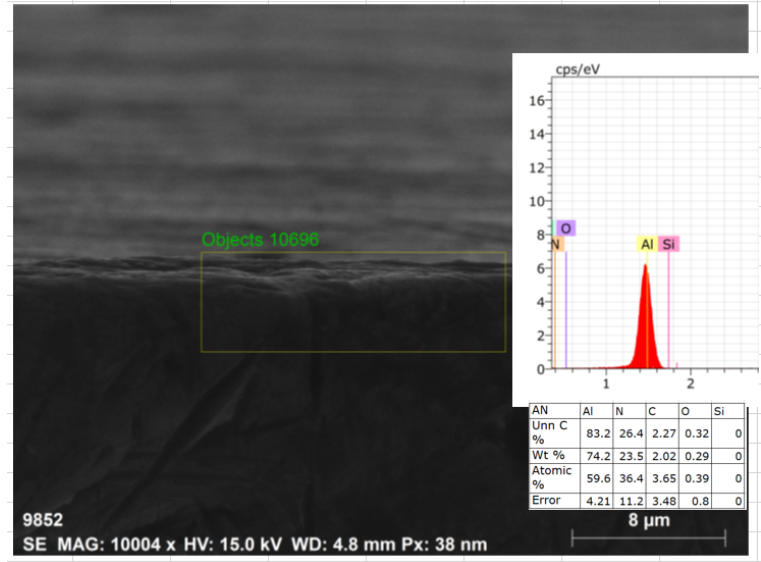

(a)

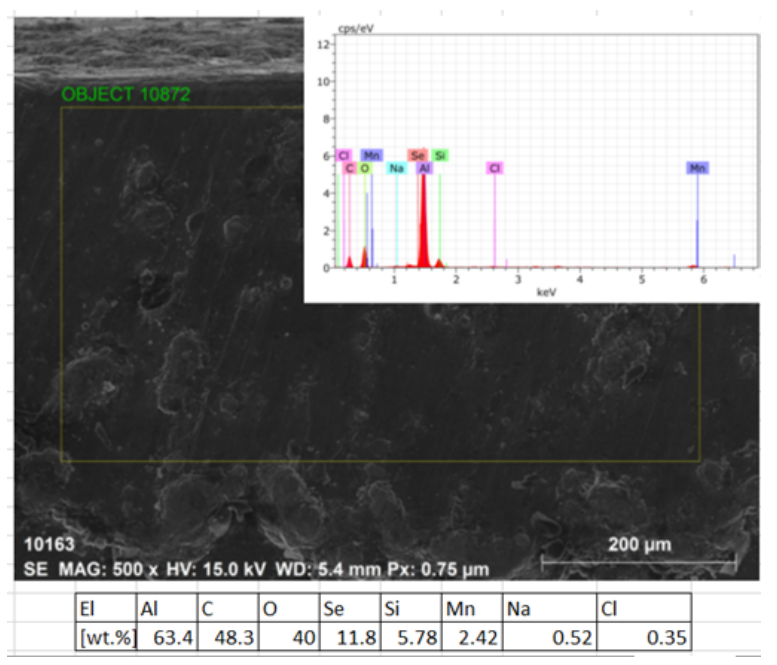

(b)

Figure 9: a) FESEM of the cross-section of the non-coated Al 6061 sample; b) FESEM of the cross-section of the coated Al 6061 sample.

absorption into the layer, which requires the catalytic activity and higher corrosion resistance of the resulting oxide layer [19]. As the voltage increases, the percentage of $\mathrm{Mn}$ in the oxide layer increases. It provides the breakage voltage required to absorb additives such as $\mathrm{Mn}$ on the $\mathrm{Al}$ substrate. According to EDAX, the percentage of the additive $\mathrm{KMnO}_{4}$ varies from 0 to 2.42 percent $w t$ in the oxide layer. The first experiments with voltage values up to $150 \mathrm{~V}$ revealed no $\mathrm{Mn}$ percentage. The Mn percent in the oxide layer increase after $150 \mathrm{v}$, which can be considered the breakdown voltage.

It is important to estimate to expand the composition study to determine the chemicals formed and their significance.

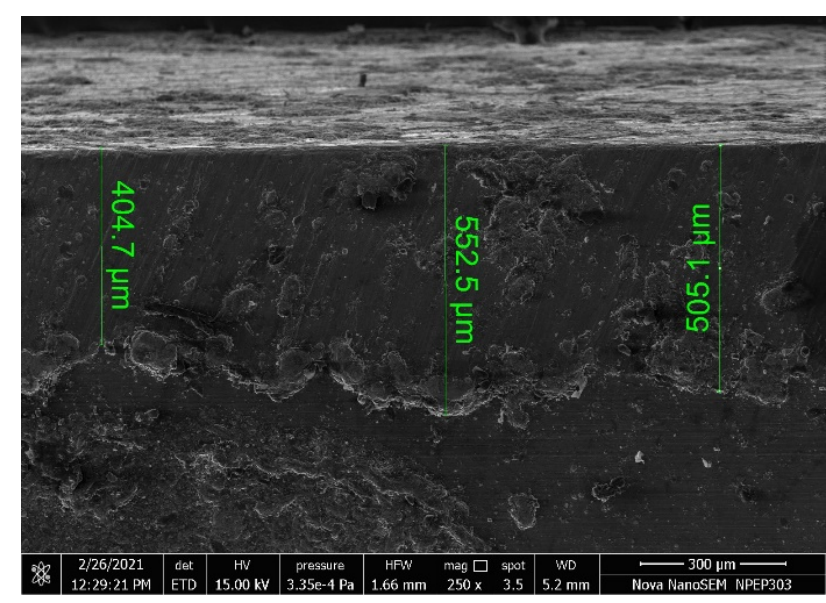

(a) Oxide layer formation at $180 \mathrm{~V}$ and $1 \mathrm{~A}$.

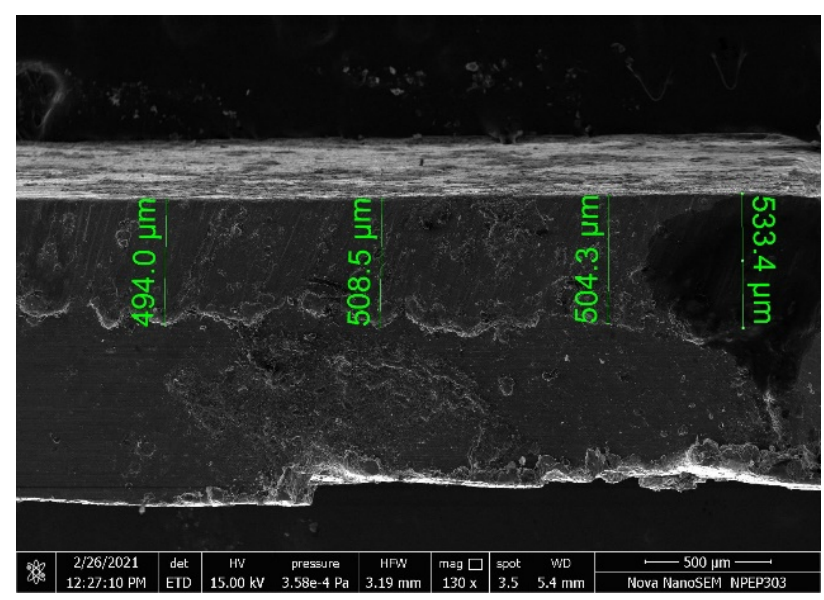

(b) Oxide layer formation at $188 \mathrm{~V}$ and $1 \mathrm{~A}$.

Figure 10: Uniformly distributed oxide layer at the cross-section of Al 6061 sample.

\section{Conclusion}

This work aims to create an oxide layer on $\mathrm{Al} 6061$ using a micro oxidation method using a DC power supply. Based on the findings of the experiments, it can be inferred that at optimal parameter values, a thin layer of oxide layer forms. Furthermore, this parameter can be modified to increase the oxide layer properties even more. The morphological investigation is the only thing that has been completed. In addition, mechanical qualities like corrosion and hardness can be investigated further.

Following are broad conclusions are from the study.

I. As per the research carried out, it has been observed that the PEMO coatings of Al6061 alloy in alkalinebased electrolyte with $\mathrm{Na}_{2} \mathrm{SiO}_{3}, \mathrm{KOH}$, and $\mathrm{KMnO}_{4}$ as additive oxide coatings are formed with Mn elements. The percentage of the doping element depends upon 


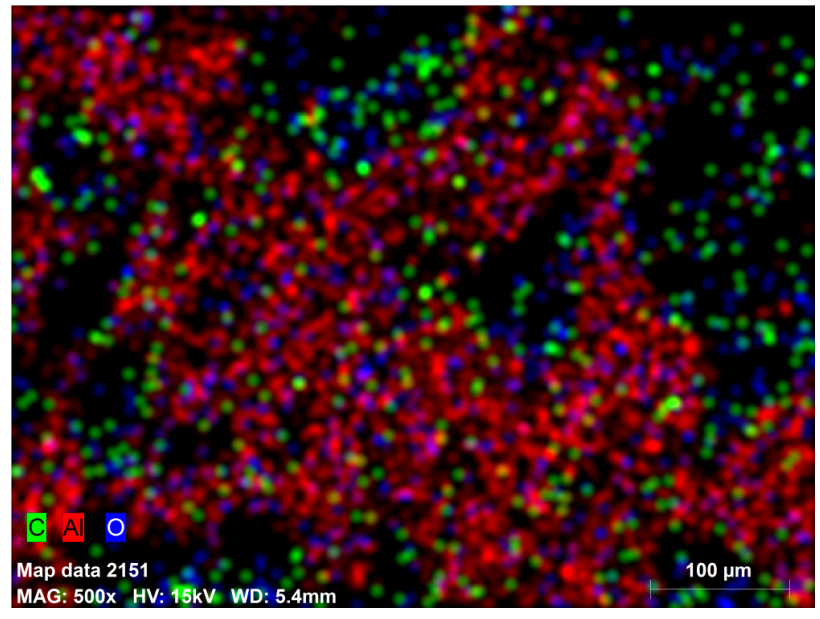

(a) SEM for all elements.

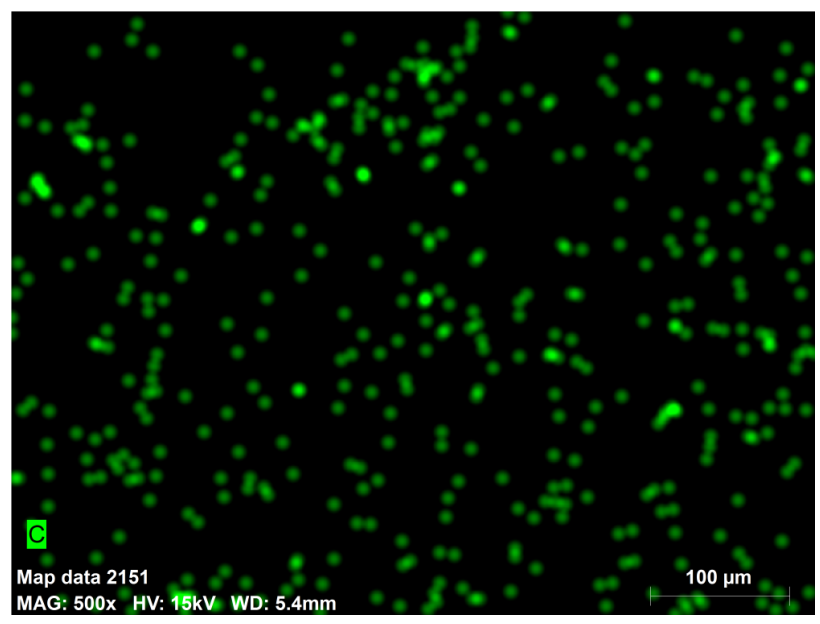

(c) Element $\mathrm{C}$ distribution.

Figure 11: EDEX mapping results with, $\mathrm{KMnO}_{4}(3 \mathrm{~g} / \mathrm{l})$ concentration.

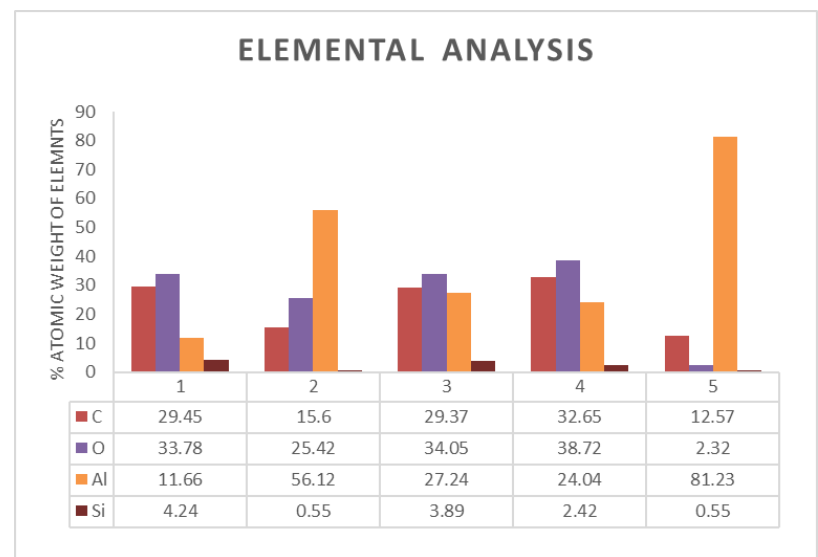

Figure 12: Percentage atomic weight of elements in oxide layer for selected samples.

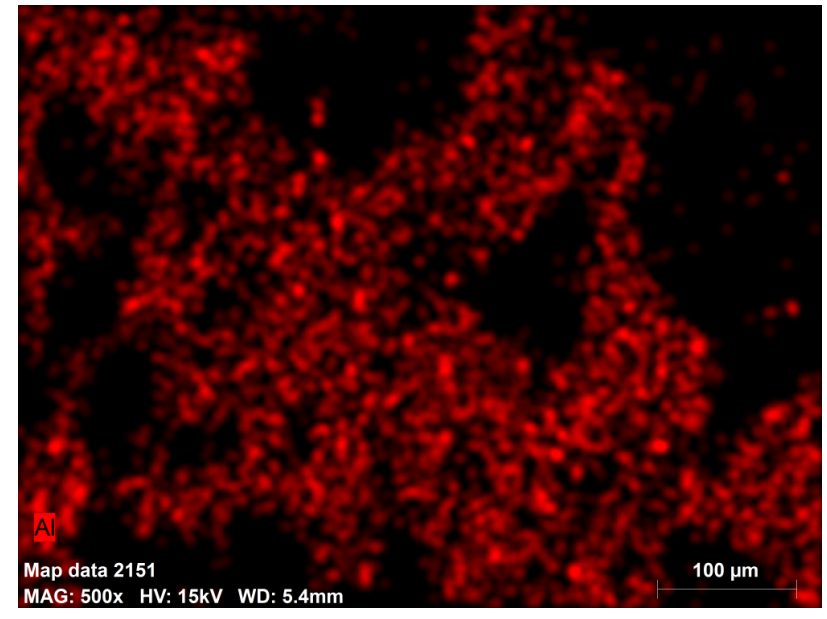

(b) $\mathrm{Al}$ element distribution.

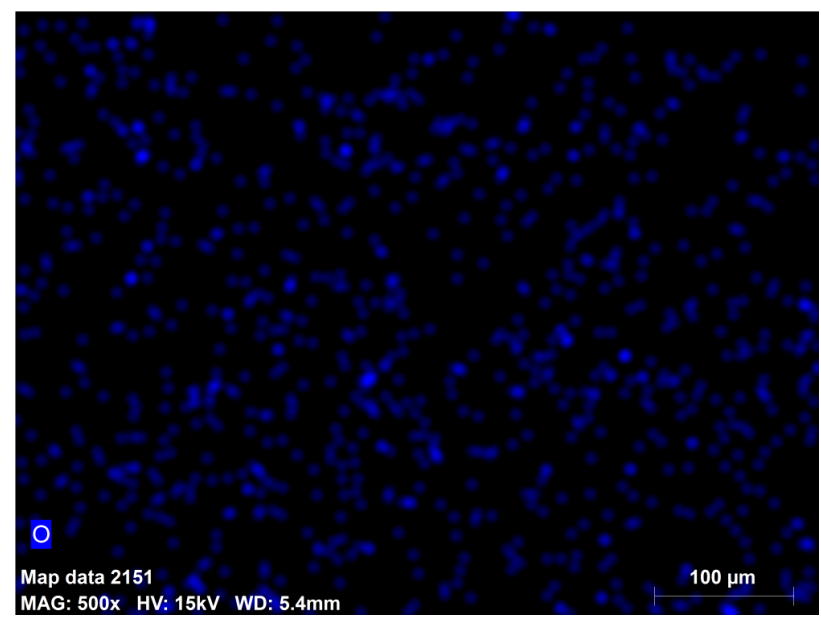

(d) Element $\mathrm{O}$ distribution.

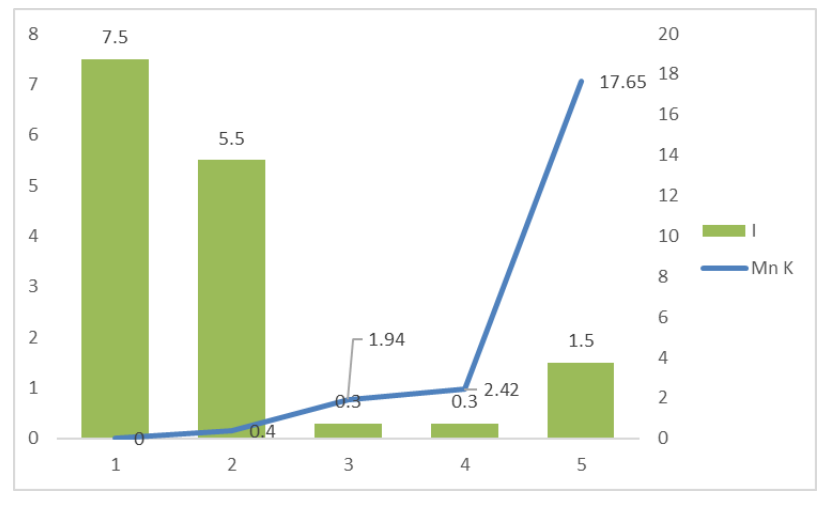

Figure 13: Percentage variation of an additive particle of $\mathrm{Mn}$ in the oxide layer. 
the composition of the electrolyte and applied voltage. The maximum $\%$ of Mn by weight was found to be 17.65 .

II. The microstructure study confirmed significant changes in the percentage of elements like $\mathrm{C}, \mathrm{O}, \mathrm{Si}$, $\mathrm{Mn}$. The changes favorably occur at $190 \mathrm{~V}$ and $1.5 \mathrm{~A}$.

III. The uniformity of the oxide layer and thickness is also checked in the cross-section layer of samples. As a result, a layer of up to 500 microns is achieved in thickness.

IV. Though the placing of two electrodes at a smaller gap created the heat, the temperature and electrolyte colling can be achieved by controlled cooling.

\section{Future work}

The more samples that are tested, the better the mechanical properties will be. The detailed analysis will demonstrate the formation of the compound and the various effects on the microstructure. More analysis can be carried in the optimized parameter ranges to study the mechanical properties of Mn particles added.

Acknowledgement: The authors would like to express gratitude to the Symbiosis International University, Pune, for financial support for the project of "Evaluation of Novel Plasma Electrolytic Micro-oxidation (PEMO) Coating Using Suspended Nanoparticles on Light Alloys" under the Research Support Fund.

Funding information: The project of "Evaluation of Novel Plasma Electrolytic Micro-oxidation (PEMO) Coating Using Suspended Nanoparticles on Light Alloys" under the Research Support Fund, is acknowledged.

Conflict of interest: The authors state no conflict of interest.

Data availability statement: The data that support the findings of this study are available on request from the corresponding author $(\mathrm{AB})$. However, the data is not available due to privacy/ethical restrictions.

\section{References}

[1] Cimpoeşu N, Trincă LC, Dascălu G, Stanciu S, Gurlui SO, Mareci D. Electrochemical characterization of a new biodegradable FeMnSi alloy coated with hydroxyapatite-zirconia by PLD technique. J
Chem. 2016;2016:1-9.

[2] Hryniewicz T. Plasma electrolytic oxidation of metals and alloys. Metals (Basel). 2018;8(12):8-11.

[3] Xia L, Han J, Domblesky JP, Yang Z, Li W. Investigation of the Scanning Microarc Oxidation Process. Adv Mater Sci Eng. 2017;2017(1):79-104.

[4] Patel VK, Bhowmik S. Plasma processing of aluminum alloys to promote adhesion: A critical review. Rev Adhes Adhes. 2017;5(1):79-104.

[5] Jadhav et al. A review of process characteristics of plasma electrolytic oxidation of aluminium alloy. J Phys Conf Ser.2021:1854. https://doi.org/10.1088/1742-6596/1854/1/012030.

[6] Aliramezani R, Raeissi K, Santamaria M, Hakimizad A. Characterization and properties of PEO coatings on $7075 \mathrm{Al}$ alloy grown in alkaline silicate electrolyte containing $\mathrm{KMnO} 4$ additive. Surf Coat Tech. 2017;329:250-61.

[7] Jadhav P, Bongale A, Kumar S. Schematic review of plasma arc oxidation process for Mg Alloy Bio Implants. IOP Conf Ser Mater Sci Eng. 2021;1017(1):012011.

[8] Wang C, Jiang B, Liu M, Ge Y. Corrosion characterization of microarc oxidization composite electrophoretic coating on AZ31B magnesium alloy. J Alloys Compd. 2015;621:53-61.

[9] Xue Y, Pang X, Jiang B, Jahed H. Corrosion and corrosion fatigue performances of micro-arc oxidation coating on AZ31B cast magnesium alloy. Mater. Corros. 2019;70(2):268-80.

[10] Hussein RO, Nie X, Northwood DO. Effect of current mode on the plasma discharge, microstructure and corrosion resistance of oxide coatings produced on 1100 aluminum alloy by plasma electrolytic oxidation. WIT Trans. Eng. Sci. 2019;124(September):316.

[11] Barati Darband G, Aliofkhazraei M, Hamghalam P, Valizade N. Plasma electrolytic oxidation of magnesium and its alloys: Mechanism, properties and applications. J. Magnes. Alloy. 2017;5(1):74-132.

[12] Matin R, Totik Y, Sukuroglu EE, Efeoglu I, Santos TG. Effects of voltage on the components of surface integrity of Al203 ceramic coatings on AA2024 by plasma electrolytic oxidation. J Adhes Sci Technol. 2020;34(18):1971-81.

[13] Shahri Z, Allahkaram SR, Soltani R, Jafari H. Optimization of plasma electrolyte oxidation process parameters for corrosion resistance of Mg alloy. J. Magnes. Alloy. 2020;8(2):431-40.

[14] Tavares MD, Vitoriano JO, Silva RC, Franco AR, Souza GB, Costa $J A$, et al. Effect of duty cycle and treatment time on electrolytic plasma oxidation of commercially pure Al samples. J Mater Res Technol. 2019;8(2):2141-7.

[15] Usman BJ, Scenini F, Curioni M. The effect of exposure conditions on performance evaluation of post-treated anodic oxides on an aerospace aluminium alloy: comparison between salt spray and immersion testing. Surf Coat Tech. 2020 Oct;399(July):126157.

[16] Lian Y, Dai X, Zhang J. Characterization of micro-arc oxidation coatings on Ti6Al4V with addition of SiC particle. Mater Res Express. 2020;7(1):16438.

[17] Yang Li Z, Bing Cai Z, Ding Y, Cui XJ, Bo Yang Z, Hao Zhu M. Characterization of graphene oxide/ZrO2 composite coatings deposited on zirconium alloy by micro-arc oxidation. Appl Surf Sci. 2020;506:144928. https://doi.org/10.1016/j.apsusc.2019.144928

[18] Yao JT, Wang S, Zhou Y, Dong H. Effects of the power supply mode and loading parameters on the characteristics of micro-arc oxidation coatings on magnesium alloy. Metals (Basel). 2020;10(11):1- 
11.

[19] Karakurkchi AV, Sakhnenko ND, Ved MV, Luhovskyi IS, Drobakha HA, Mayba MV. Features of plasma electrolytic formation of manganese- And cobalt-containing composites on aluminum alloys. Adv Mater Sci Eng. 2019;2019:1-13.

[20] Gao G, Li Y, Li C, Hu D, Li Z, Xi Z. Influence of KMnO4 concentrationon infrared emissivity of coatings formed on TC4 alloys by micro-arc oxidation. Materials (Basel). 2017 Nov;10(11):E1301.

[21] Sharma A, Jang YJ, Jung JP. Effect of $\mathrm{KOH}$ to $\mathrm{Na} 2 \mathrm{SiO} 3$ Ratio on $\mathrm{Mi}$ crostructure and Hardness of Plasma Electrolytic Oxidation Coatings on AA 6061 Alloy. J Mater Eng Perform. 2017;26(10):503242.

[22] Jensen F, Kongstad I, Dirscherl K, Gudla VC, Ambat R. High frequency pulse anodising of recycled 5006 aluminium alloy for optimised decorative appearance. Surf Coat Technol; 2019;368:4250. https://doi.org/10.1016/j.surfcoat.2019.04.024

[23] Hou PY, Berkeley L, Niu Y. Analysis of Pore Formation at Oxide - Alloy Interfaces - I : Experimental Results on FeAl Analysis of Pore Formation at Oxide - Alloy Interfaces - I : Experimental Results on FeAl. Oxid Met. 2003;59: https://doi.org/10.1023/A.
[24] Shin DJ. S.G.; Min, "A Study on the Reduction Behavior of $\mathrm{FeO}$ by Analyzing Pore. Metals (Basel). 2021;11(414): https://doi.org/10.3390/met11030414.

[25] Tsai DS, Chou CC. Influences of growth species and inclusions on the current-voltage behavior of plasma electrolytic oxidation: A review. Coatings. 2021;11(3):1-21.

[26] Yerokhin AL, Nie X, Leyland A, Matthews A, Dowey SJ. Plasma electrolysis for surface engineering. Surf Coat Tech. 1999;122(23):73-93.

[27] Fowler R, Howell J, Passman F, Mcguire N, Aikin AR. HITEC ® 521 38 Solid coatings: Not just for space vehicles anymore; 2019.

[28] Sieber M, Simchen F, Morgenstern R, Scharf I, Lampke T. Plasma electrolytic oxidation of high-strength aluminium alloyssubstrate effect on wear and corrosion performance. Metals (Basel). 2018;8(5):1-17. 